\title{
Banning Smoking in Public Places under Ethiopian Legal Framework: Some Evidences from Hawassa City
}

\author{
Edilu Shona \\ School of Law, Hawassa University, Hawassa, Ethiopia \\ Email: edilu2005@gmail.com
}

How to cite this paper: Shona, E. (2017). Banning Smoking in Public Places under Ethiopian Legal Framework: Some Evidences from Hawassa City. Beijing Law Review, 8, 526-550. https://doi.org/10.4236/blr.2017.84029

Received: November 2, 2017

Accepted: December 24, 2017

Published: December 27, 2017

Copyright $\odot 2017$ by author and Scientific Research Publishing Inc. This work is licensed under the Creative Commons Attribution International License (CC BY 4.0).

http://creativecommons.org/licenses/by/4.0/

Open Access

\begin{abstract}
Despite the fact that banning smoking in public places has been justified for smoking poses massive problems of health, welfare and ecology on both smokers and SHS elsewhere in the world, the issue of smoke banning in Ethiopia has not attracted the attention of researchers and the academics. Therefore, the overriding objective of this article is to explore legal and institutional frameworks banning smoking in public places to combat smoking as a public threat in Ethiopia. The study was predominantly undertaken through doctrinal legal research methodology. Accordingly, more than 15 proclamations, regulations, directives and legal notices on tobacco control were reviewed as primary legislative sources. Various international treaties and conventions and WHO reports, journal articles and books have been explored as secondary data. The result of this research revealed that legal restriction and controlling of tobacco product was introduced 90 years ago and banning smoking in public places is a recent phenomenon introduced in 2013 by virtue of Regulation No. 299/2013 and Ethiopia ratified the FCTC to strengthen the campaign. But enforcement of these legal measures flawed due to the existing laws allow smoking in designated area and failed to implement despite the implementation is proved being ineffective of protecting the SHS elsewhere. On top of that, it is found that there is no clearly defined legal and administrative measure to be taken if the law is not complied. Institutionally, some evidences in Hawassa city revealed that the department of health is not in a position to enforce smoke banning legislation due to lack of clear measures against noncompliance, lack of capacity, nonexistence of local ordinance at the regional level and lack of clearly defined duties and responsibilities of the enforcing organs. Therefore, this study concluded that banning smoking in public places under Ethiopian legal framework is not comprehensive and not effectively implemented to ensure its basic objectives of protecting the public from tobacco
\end{abstract}


threat in general and SHS in particular.

\section{Keywords}

Banning Smoking, Tobacco Threat, FCTC, FMHACA, Legal and Institutional Framework, Proclamation, Tobacco Control Directive, Second-Hand Smoke (SHS), Hawassa City

\section{Introduction}

Globally, tobacco products kill about 6.4 million people a year (WHO Global Report, 2012). If the current trends are unchecked, this figure is expected to rise to 10 million per year by the 2020 s or early 2030 s with $80 \%$ of those deaths occurring in developing countries (Ibid). Tobacco kills more people than AIDS, legal drugs, illegal drugs, road accidents, murder, and suicide combined and half of all lifetime its loyal users ${ }^{1}$. The threat is compared to be equal to the Titanic sinking every 27 minutes for 25 years, or the Vietnam War death toll every day for 25 years (Boyle, Nigel, Jack, John, \& Witold, 2004).

Moreover, contrary to what many people might think, "most of these deaths are in low and middle-income countries" and the gap in deaths between low and middle-income countries and high-income countries is expected to widen further over the next several decades if we do nothing (WHO Report, 2009). If current trends persist, tobacco will kill more than 8 million people worldwide each year by the year 2030 , with $80 \%$ of these premature deaths in low- and middleincome countries (Ibid). While the trend of smoking prevalence is falling in high-income countries, due to restrictive legislation enforcement, in contrast however, it is increasing by over $3 \%$ per year in low and middle-income countries due to a concerted tobacco companies market focus in the developing countries.

Secondly, the effect of tobacco is not limited to its smokers; it also endangers the life of others in form of passive smoking (WHO Report, 2009). It is argued that any exposure to SHS is harmful (Chapman, 2007). In similar vein, Jaloha (2008) argued that "secondhand smoke" (herein after referred as, SHS) is the inhalation of tobacco smoke by nonsmokers and has been variously referred to as "passive smoking", or "environmental smoking. According to him, second-hand tobacco smoke is the smoke emitted from the burning end of a cigarette (side stream smoke) or from other tobacco products, usually in combination with the mainstream smoke exhaled by the smoker, and has similar components to inhaled or mainstream smoke. Accordingly, reversing the problem through legal and policy framework has been taken as irreplaceable remedy in many aspects. The most important global move on tobacco control history

${ }^{1}$ World Health Organization, Tobacco Free Initiative, "The Tobacco Atlas," Section 9, "Deaths," available at http://www.who.int/tobacco/en/atlas11.pdf Accessed on 12/06/2016. 
was made in May 2003. The member states of the World Health Organization (hereinafter referred to as, WHO) challenged the global spread of tobacco by adopting an international tobacco control treaty, the Framework Convention on Tobacco Control (herein after referred as, FCTC) (Meier, 2004). The FCTC is an international treaty created within the framework of the WHO, whose end goal is the eradication of the smoking epidemic ${ }^{2}$. Moreover, the preamble of the FCTC provides that the aim of its existence is to protect present and future generations from the devastating consequences of tobacco consumption and the exposure to tobacco smoke and it requires the member states to ban smoking in public places.

Although it is difficult to generate accurate figure of smoking and its related effect on both smokers and SHS in Ethiopia, the prevalence of smoking in Ethiopia is one of the lowest in the world as only $0.8 \%$ of Ethiopian women and $8.1 \%$ of Ethiopian men smoke any tobacco product (Lakew \& Haile, 2015). This figure roughly covers $4.1 \%$ people are attached with tobacco use approximately endangering four million one hundred thousand people with smoke related threat and several millions of SHS who are involuntarily affected ${ }^{3}$. Similarly, the Global Youth Tobacco Survey showed that SHS exposure is estimated about (16.7\%) students live in homes where others smoke in their presence and about $44.6 \%$ are exposed to smoke in public places and one in ten have parents who smoke (GYTS Report, 2005). This study already revealed that tobacco use in Ethiopia is in increasing trend among the public in general and the youth in particular (Ibid). By the same token, another study conducted in 2011 in Addis Ababa revealed that among majority students who joined high school education $41.5 \%$ start smoking and $18.5 \%$ of primary level students are addicted to cigarette addiction $^{4}$. It is also noted that young Ethiopians usually start smoking while still in high school due to peer pressure among friends, although the prevalence significantly increasing among students at colleges and universities ${ }^{5}$.

On top of this, a new survey released at the end of October 2017 revealed that there are around 3.7 million tobacco users and 2.9 million adult cigarette smokers in the country (Abiye \& Dawit, 2017). It is stated that the Global Adult Tobacco Survey (GATS), conducted in conjunction with the government of Ethiopia, is the country's first survey of adult tobacco use. The survey also shows that nearly one-third of adult Ethiopians are exposed to secondhand smoke at work

${ }^{2}$ The WHO [World Health Organization] (2003), "WHO Framework Convention on Tobacco Control (FCTC)", Available at: www.who.int/fctc/text_download/en/index html Accessed on $14 / 05 / 2015$.

${ }^{3}$ Smoking rates vary significantly across Ethiopia. In some areas, the number of men smokers is way higher than the reported national prevalence of smoking in Ethiopian men of less than 10\%; and it is higher than the prevalence of smoking for men in many other countries.

${ }^{4}$ (Addis Admas Newspaper, 2015). “Ph. meaning Students in Addis Ababa are vulnerable to serious ethical deterioration" available at: http://www.addisadmassnews.com/ Amharic version which is an official language and translation by the author.

${ }^{5}$ (Sudan Tribune, 2015). http://www.sudantribune.com/spip.php?article53625 
(Ibid). Secondhand smoke exposure is especially high at bars and nightclubs (60.4\%), with significant exposure at restaurants (31.1\%) and universities (29.4\%) as well (Ibid). Accordingly, the survey on adult tobacco use also suggested that millions of Ethiopians are exposed to secondhand smoke and it is an alarming trend that requires serious action from the government.

The prevalence of smoking in Hawassa city is not well documented and nor comprehensively studied. But a school based cross sectional study was conducted on the prevalence of cigarette smoking among adolescents in Hawassa and Jimma towns found that $28.6 \%$ ever smokers, and $17.2 \%$ current smokers. In addition, more than half $60.8 \%$ of adolescents were exposed to tobacco smoke from others in public places (Dereje, Abazinab, \& Girma, 2014). According to the study "it is possible to conclude that the prevalence rate is increasing in its spread, the gap between male and female is decreasing and environmental exposure to tobacco smoke is wide spreading" (Ibid). There is no doubt such number is very critical and significant number of population are exposed to the SHS and the hazardous effect of smoking is inevitable to happen. If the current trend is not controlled "many of those adolescents who currently smoke would have to endure a life time addiction and may die prematurely from tobacco-related diseases" (Dereje, Abazinab, \& Girma, 2014).

Moreover, the Ethiopia's premier tobacco company the National Tobacco Enterprise (herein after referred as, NTE) has increased its production of cigarettes from 4 billion to 6 billion per year ${ }^{6}$. The fact that the NTE increased its production of cigarettes from 4 billion a year to 6 billion a year recently implies that smoking is rising in Ethiopia. Therefore, the preamble of (Tobacco Control Directive No. 28/2015) provides tobacco is a growing public health concern in Ethiopia which requires early intervention despite the nonexistence of concrete data that show the extent of deaths caused by smoking. In this regard, the legislative restriction or banning smoking in public places have been justified for several scientific and philosophical grounds that worked elsewhere works in Ethiopia too; for the fact that smoking has been proved to pose massive problems of health, welfare and ecology (Goodman, 2005). It is the only legally available consumer product which kills half of its consumer even if used entirely as intended (WHO Report, 2009). Despite such facts the issue of legislative banning of smoking in Ethiopia has not been researched nor attracted the attention of the academics and the public at large. Therefore, this piece is believed to bring a social-legal, political and academic significances where researching on restricting smoking in public places drew insignificant attention of society and academic at large in the Ethiopian context. Among others, it indicates enforcement bodies and policy makers the role of laws to protect the public and smokers

${ }^{6}$ The history of cigarette consumption in Ethiopia shows a phenomenal growth since the first production was begun during the era of Menelik II. The first factory was erected early in the 20th Century in the city of Dire Dawa, $555 \mathrm{~km}$ east of the capital. This factory, owned by an Armenian native, was moved to Addis Ababa in 1931, to settle in a locality used to be called Benin Sefer. 
by suggesting the relevance of effective legislative banning smoking in public places and could provide useful information on how to enhance legislative and institutional framework so as to avoid social and economic threat of smoking. Moreover, it would be a prior scientific and legal research on the area and attracts the attention of the academic and other concerned public advocates to undertake further holistic study.

Therefore, the main objective of this article is, therefore, to explore the legislative and institutional framework banning smoking in public places in Ethiopia taking some evidences from Hawassa city. In so doing, it has four parts. The first part deals with the justifications behind banning smoking in public places and debates against it. The second part discusses the global legislative responses in restricting smoking in general and some practical success history of some countries in enforcing such laws. The third section is devoted for the discussion of Ethiopian experience in banning smoking in public places taking the legislative and institutional framework into account and some evidences from the city of Hawassa. And the last of part this piece is summarized by conclusion and few points of suggestions.

\section{Banning Smoking in Public Places: Justifications}

As reiterated earlier, tobacco product kills about 6.4 million people annually and its fatality is not limited to smokers alone; there are also reliable scientific evidences that SHS poses serious health problem. But such public threats have been refuted continuously. Prior to the initiatives of the FCTC as a global response, there were various legislations that banned smoking in public places. The most important reason for those early legislations on banning smoking in public places was apparently designed to prevent fires. Examples of such legislation existed in Alexandria, Egypt (1908), Sao Paulo, Brazil (1950), and the State of New Delhi, India (1953) (Roemer, 1993) as cited in (Boyle, Nigel, Jack, John, \& Witold, 2004). The antismoking legislation of the late $19^{\text {th }} \mathrm{C}$ was based largely on moral opposition to smoking (Rabin \& Sugarman, 2001). In recent years, however, the primary argument justifying regulation of tobacco products have been the health costs and risks associated with tobacco use. Thus, arguments favoring banning smoking public places rest on a combination of scientific, moral, and public policy grounds (Ibid).

As a scientific justification, there is a clear scientific evidence that smoking causes serious health consequence as reiterated in the introductory section. On top of this smoking brings a likely damage against SHS beyond the negative effect of smoking on smokers (Prabhat, Frank, James, Vendhan, Prakash, Richard, Samira, et al., 2006). There are various evidences to augment this assertion. In the first place, SHS is estimated to kill 600,000 people worldwide each year through increased heart disease, respiratory ailments, asthma, and lung cancer (Mattias, Jaakkola, Woodward, Peruga, \& Prüss-Ustün, 2011). Breathing even a little SHS can be dangerous and protecting people from exposure to SHS (WHO 
Report, 2009). Secondly, the effect of SHS more affects vulnerable groups of society such as children and women. Data from a study on the issue shows of all deaths attributable to SHS, approximately $47 \%$ occur among nonsmoking women and 27\% occur among nonsmoking children (Mattias, Jaakkola, Woodward, Peruga, \& Prüss-Ustün, 2011). Thirdly, exposure to SHS at any level often occur is associated with lung cancer, cardiovascular disease, stroke, and other illnesses in nonsmokers (Rabin \& Sugarman, 2001). Employees are at especially high risk of harm from SHS, given their constant exposure in places that allow smoking. Workers are involuntarily exposed to smoke and do not have a choice about avoiding smoke if they want to keep their jobs ${ }^{7}$. Therefore, it is stated that "creating $100 \%$ smoke-free environments is the only way to protect people from the harmful effects of second-hand tobacco smoke" (WHO Report, 2009).

Accordingly, reducing population exposure to SHS is taken as a key public health priority of many governments and adopted laws and policies that restrict or completely prohibit smoking in a variety of public places such as restaurants and bars ${ }^{8}$. Towards this benefit (Carpenter, Sabina, \& Casey, 2011) argued that public-place smoking restrictions are the most important nonprice tobacco control measures worldwide. Such restriction on smoking in public place is the most important nonprice policy to reduce death and disease caused by tobacco use, ahead of advertising bans, information campaigns, warning labels, and quitassistance for current smokers (WHO Report, 2009).

Beyond the scientific arguments, there are also conceptual justifications for legislative banning of smoking in public places mainly related with public policy issue. For instance, Chapman, Borland, Scollo, Brownson, Dominello \& Woodward (1999) argued that reducing exposure to second-hand tobacco smoke benefits health in many ways, such as by significantly reducing tobacco consumption and by reducing the likelihood that young people will progress to established smoking. Thus, legislative restriction of smoking at public places are justified to save vulnerable children who simply follow smokers at their environment and to reduce the frequency of smokers enabling them quitting smoking for good (Ibid). As the public supports attempts to reduce adolescent smoking and exposure to SHS, children are vulnerable groups of society who always attempt to replicate what they perceive at their compound. Among children exposed SHS tobacco smoke, there is a $50 \%-100 \%$ higher risk of acute respiratory illness, higher incidence of ear infections and an increased likelihood of developmental disabilities and behavioral problems (WHO Report, 2009). Globally, over 165,000 children die every year from lower respiratory infections, middle ear infections, and asthma caused by SHS (Ibid). To be sure, a question of banning smoking in public places is not hardly challenged in terms of schools, day care centers, and transportation facilities who mostly host the vulnerable groups of society.

${ }^{7}$ (Smoke-Free Environments, 2011): Health Harms of Secondhand Smoke October http://www.tobaccofreecenter.org/, Accessed 1/12/2016.

${ }^{8}$ Smoke-free Environments Essential Facts, 2011, WHO.

https://www.tobaccofreekids.org/assets/global/pdfs/en/SF_facts_en.pdf 
The other justification takes smoking in itself is beyond a personal choice. This is a counter argument against those who claim banning smoking is related to the fact that smoking is all about individual life style and government should not smack paternalism beyond telling smoking harms health. The opponent of banning smoking in public places argued that the role of government should not exceed from educating and counseling and shouldn't include paternalistic nature as it is all individual's free decision to smoke or not and banning smoking in

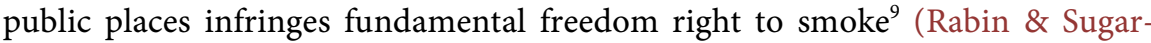
man, 2001).

For several reasons, however, limiting the public spaces where an individual can smoke is not against individual liberties. In the first place, smoking as individual choice is unacceptable as it is proved to result in a powerful addiction that impair autonomous decision-making and impedes voluntary choice, an individual's decision to continue smoking cannot be said to be the result of a truly free and informed choice (Meier, 2004). Nicotine addiction is a chronic illness, necessitating the state provision of medical resources to enhance individual autonomy in deciding whether or not to continue smoking (Ibid). Since exposure to passive smoking is a public health hazard, it is the responsibility of a given government to protect the public from such exposure. Limiting the public spaces where an individual can smoke is not a significant intrusion upon individual liberties, especially when balanced against the public's right to breathe clean air. Secondly, it should be noted that tobacco consumption results in negative externality on nonsmokers and the government to say the least. Smokers and tobacco producers through their product causes additional public cost that they do not cover in any manner. Such laws are not dictating personal choices; they are merely limiting the effects of those choices on the public. In this regard $\mathrm{Wu}$ Chuan, 2009) argued that "the personal freedom to smoke is not an absolute right. Individuals' freedom to smoke must be balanced against the responsibility of the state to protect public health, the expense incurred by the state in doing so due to tobacco use, and the pursued public health benefits. As far as the state can prove that a compelling interest that was substantially furthered by governmental smoking restrictions, it is then justified to restrict individuals' freedom to smoke in exchange for greater utility". Therefore, it could be strongly captured that common-sense dictates that the protection of third parties, especially nonsmokers, from the harmful effects of SHS must outweigh the individual's right to smoke anywhere he or she pleases (Rabin \& Sugarman, 2001).

Lastly, banning smoking in public places is also attached with enhancing the smoke cessation program of the smokers. This has been practically proved as such laws generally reduce the quantity of cigarettes smoked by $5 \%$ to $25 \%$ and reduce prevalence rates up to $20 \%$ in workplaces (Prabhat, Frank, James, Vend-

${ }^{9}$ Similarly, the NTE as tobacco industry claimed that it is up to the individuals whether to choose to go hell or to paradise after following a preacher's message and what matters remains the way how preach not the way how to regulate in many occasions. 
han, Prakash, Richard, Samira, et al., 2006). If smoke-free laws are enforced, it changes the behavior of both smokers and nonsmokers develop a preference for smoke-free environments. It is submitted that comprehensive restriction of cigarette smoking has been estimated to reduce population smoking rates by $5 \%$ $15 \%$ and can also lead to changes in social norms regarding smoking behavior, especially among youths (Carrell, Carolyn, Len, Juliet, \& Sandy, 1998). There are also smokers who contended that restriction on smoking gave them opportunities towards their attempt to quit and have even been shown to favor smoke-free workplaces and public places (Boyle, Nigel, Jack, John, \& Witold, 2004). Therefore, albeit the main goal of banning smoking in public places is to reduce the public's exposure to SHS; banning enhances a decrease in the overall prevalence of smoking, a reduction in the daily consumption of tobacco products, an increased rate of smoking cessation, a decreased number of relapses from attempts to quit (Ibid).

\subsection{Global Responses against Tobacco Threat: The Framework Convention on Tobacco Control}

The issue of banning in public places became the concern of international community since 1970s. Yet, the most significant move was made in 2003, while the member states of the WHO confronted the global spread of tobacco by adopting the FCTC (Meier and Donna, 2006). The WHO, FCTC was the first treaty negotiated under the auspices of the WHO and entered into force in 2005 (Ibid). It is one of the most rapidly embraced UN treaties and represents a paradigm shift in developing a regulatory strategy to address addictive substances (Meier, 2004). In contrast to other international treaties, the WHO FCTC asserted the importance of demand reduction strategies as well as supply issues and thus established a framework for an integrated multi-sectoral response to a grave public health issue (Meier \& Donna, 2006). It is the first public health treaty which became one of the most rapidly and widely embraced treaties in the history of the United Nations for 180 states endorsed it $^{10}$.

The preamble of this treaty asserts a determination "to give priority to the right to protect public health". Even when tensions arise between the right to health and other rights or interests including individual interest, however, the FCTC prioritizes the protection of public health (Serrano, 2008). One clear example comes from Art. 8 protection from exposure to tobacco smoke in public places (Cabrera \& Gostin, 2011). By restricting smoking in public locations, the state specifically duty bound to protect smokers and nonsmokers alike from the harm that SHS represents.

\subsection{Banning Smoking in Public Places: A Lesson from Successful Countries}

As reiterated elsewhere in this work, various justifications made against smoking

\footnotetext{
${ }^{10}$ Status of the WHO Framework Convention on Tobacco Control (FCTC), Accessed on 3/5/2016.
} 
to protect the public health and it is beyond question. But what still remains is about when, how, and under what circumstances the state should exercise that power. Some countries have comprehensively restricted smoking at public places without any exemption. Others have conceived this to mean something as simple as requiring hospitals to provide a smoke-free indoor environment, while some others have adopted comprehensive regulations that prohibit smoking in all indoor workplaces, including bars and restaurants. In any case, smoke free laws is one of the most cost-effective ways to reduce the enormous and growing burden of noncommunicable disease anywhere in the world (Sims, Maxwell, Bault, \& Gilmore, 2010).

One of significant ride is made to protect the right to safe and healthy working conditions would oblige any state to implement regulations to minimize the occupational health hazards associated with tobacco production (Cabrera \& Gostin, 2011). In addition, it would mandate that a state protect its citizens from exposure to SHS in the workplace ${ }^{11}$. Moreover, at least 385 million people are protected by $100 \%$ smoke-free laws in countries, states, and cities are large and small and represent many cultures, climates, and income level (WHO Report, 2011).

Countries such as Australia, Canada, and Turkey, have successfully passed and implemented $100 \%$ smoke-free laws. It is appropriate to protect all people from death and illness caused by SHS, no matter what country they live in as there is no safe level of exposure to SHS (Rockville, 2010). As of 2012, 44 countries have policies ensuring that all public places are $100 \%$ smoke free and it has been proved that 350 million people have been protected as a result (Agbenyikey, Wellington, Gyapong, Travers, Breysse, McCarty et al., 2010). Thus, it could be argued that the "only effective way to protect the public from SHS is enacting comprehensive smoke-free laws that cover all indoor workplaces and public places, including all restaurants, bars, and other hospitality venues" 12 .

It is clear that the legislative restrictions on where and in what circumstances have been dealt and proved effective in several states around the world. The best experience has been invoked from the two developing countries. Mauritius Africa and Uruguay both from developing country showed a dramatic paradigm shift after it adopted the FCTC and by now it is one of the leading smoke free state in the world. Since 1999 enacting seven new and improved legislations, Mauritius has emerged as one of the regional leaders in tobacco control to be exemplified for its strong government commitment to enforce smoke free legislation in public places (Drope, 2011). By the same token, Uruguay has also proved the success of smoke free campaign and after legislative measures; it

\footnotetext{
${ }^{11}$ Ibid, a Canadian court recognized that exposure to second-hand smoke infringed upon a right to just, equitable, and satisfactory conditions of work and compensated a non-smoking waitress, who had acquired lung cancer as the result of her exposure to secondhand smoke while working.

${ }^{12}$ World Health Organization (2007), Protection from exposure to second-hand smoke: policy recommendations.
} 
became the first $100 \%$ smoke free country in the Americas ${ }^{13}$. It was reported that Uruguay has saved "3.5 million of lives from its smoke free policy since 2006 though the level of SHS in Uruguay" which was among the highest in Latin America before the legislation come into force (Ibid).

\section{Legislative and Institutional Framework on Tobacco Product in Ethiopia}

Although there is lack of a holistic research, as a matter of fact, controlling tobacco production was introduced during the era of Empress Zewditu by the Tobacco Regie Regulation $1928^{14}$. The objective of this regulation was simply to provide how tobacco is produced under the monopoly. After 12 years, the government passed another law known as the Tobacco Regie Proclamation which gives diversities of power to the regulatory body ${ }^{15}$. According to Proclamation No 30/1942 the Regie was established as a State Monopoly to among other things, purchase, preparation, manufacture, sale import and export of tobacco, whether in its natural and in the shape of cigarette, cigars, chives serving in the manufacture of tobacco products. This legislation prohibited the import, export or sell of any monopolized article which included, among others, tobacco except under license from the Board or by such other authorities as may be designated by the Ministry of Finance.

From the institutional perspective, Legal Notice No. 227/1959, mandated the Board to issue the license. Moreover, Art. 2 (E).) of Decree No 37/59, also provided for punishment on anyone contravening the provisions thereof with a fine not exceeding ten thousand Maria Theresa tellers or imprisonment not exceeding two years.

\footnotetext{
${ }^{13}$ Smoke free Success Stories: Spotlight on smoke free countries, Global Smoke Free Partnership, Available at: http://www.tobaccofreecenter.org/. Accessed on 4/5/2016. On September 9, 2004, Uruguay ratified the Framework Convention on Tobacco Control. The process of ratification provided a good opportunity for the public and policy makers and the same year, a presidential decree (Decree 98/004) declared that all health establishments should be $100 \%$ smoke-free environments. The experience of Uruguay shows that the implementation of $100 \%$ smoke-free environments is not only desirable, but also possible, even in countries in Latin America with high prevalence rates and especially when there is political will and the support of civil society.

${ }^{14}$ Tobacco Regie Regulation provided with eight chapters and thirty-four Articles, these regulations put in place the legal and institutional infrastructure for tobacco farms including matters relating to production of the tobacco leaf, licensing of tobacco farmers, distribution and training of traders engaged in the business. The Regulations also carry provisions for granting monopoly of cigarettes, cigars and cigarette papers, procedure for importation and exportation of tobacco products from and to Ethiopia, with the then Ministry of Agriculture assuming the responsibility of implementing the law.

${ }^{15}$ (Proclamation No 30/1942) A Proclamation to Establish a State Monopoly in Respect of Tobacco, Matches and Pocket Lighters. This law established a state monopoly in the name of a Regie, the predecessor of the National Tobacco Enterprise, which was vested with exclusive powers in the following areas: 1) the purchase, preparation, manufacture, sale, import and export of tobacco, whether in its natural form or in the shape of cigarettes, cigars, chine serving in the manufacture of tobacco; 2) the manufacture, possession and trade in paper for the preparation of cigarettes; 3 ) the manufacture, possession or trade of machinery and detached pieces of machinery for machines serving in the manufacture of tobacco; 4) the manufacture, possession and trade of matches, pocket lighters, detached parts of pocket lighters, petrol phials serving for the use of pocket lighters and flints for pocket lighters.
} 
After 30 years, this law was repealed by Proclamation No. 197/1980 and the National Tobacco and Matches Corporation was established. The rationale behind the establishment of Corporation was primarily, to enable it carrying out the manufacturing, trading and other related activities. As its predecessor, Art 7 of this Proclamation conferred the NTE an exclusive right to grow and process tobacco for the satisfaction of the country's needs and foreign exchange. Thus, the objectives of these laws were not aimed at the protection of the public from smoking and nor acknowledged such health threat as serious public health concern.

Similarly, it is envisaged that the NTE was established with the exclusive right to manufacture, import and export tobacco and tobacco products Proclamation No 37/92. There have been various laws enacted including Legal Notice No, 70/1945; Legal Notice No. 227/1959; Proclamation No. 197/1980; Proclamation No. 37/1992; Proclamation No. 181/1999. In similar vein, the NTE was mandated to regulate tobacco product as sole producer of the product and it controlled others issuing the license. According to Proclamation No. 181/1999, the objective of the enterprise was similar with its predecessor and meant to promote the prevalence of tobacco products in any manner so as to satisfy the needs of foreign exchange.

The NTE share company was established to strengthen the monopoly over production and distribution of tobacco and tobacco products in the country ${ }^{16}$. The institutions mandate to regulate tobacco product were largely manufacturer and the producer of the product. These laws were in no way in conformity with the FDRE Constitution which provides that "all persons have the right to a clean and healthy environment" (Proclamation No. 1/1995, FDRE Constitution Art, 44, 1).

As we observed in the previous section, tobacco use control is largely related with the right of workers in healthy environment. The right to a healthy and safe work environment is also provided in the FDRE Constitution (Ibid, Art 42.2). The government is further expected to protect and promote the health, welfare and living standards of the working people (Ibid Art, 89, 8). This provision envisages that the public is entitled to live where their lives won't be at risk. Accordingly, these prior legislations were against the constitutional protection towards the public large. The regulatory regimes seen above, aimed to regulate marketing aspect of tobacco products from the economic aspects to a single monopoly of public enterprise and it was noticed that the supplier of tobacco product was given the power to regulate its product including licensing of tobacco product for other bodies who may be engaged in the business of tobacco product let alone curbing health and other multifaceted problems. The content of these laws promoted tobacco product for Ethiopian society attaching tobacco production with matches pocket lighters, detached parts of pocket lighters, petrol phials

\footnotetext{
${ }^{16}$ Article 2 of Proclamation 181/1999 thus provides that the Monopoly right of the National Tobacco Enterprise in respect of the purchase, preparation, manufacture, sale, import and export of tobacco and tobacco products. The Ministry of Finance and Economic Development, (MoFED) is the major shareholder with $78 \%$ of the total shares; Sheba Share company retaining the balance $22 \%$ of the shares. But currently $40 \%$ of the government's share was transferred to Japanese Tobacco International (JTI) and only $38 \%$ remained as its share.
} 
serving for the use of pocket lighters and flints for pocket lighters. In general, the above legislative measures were literally meant to regulate the economic benefit of tobacco products under the monopoly of public enterprise. Therefore, this writer strongly holds that the rationale behind legislative failure to ban smoking in any place under the Ethiopian legal framework until 2013 was for the sole purpose of sustaining the economic benefit of tobacco products under the monopoly of public enterprise.

\subsection{Legislative and Institutional Framework after 2009}

Although regulation of tobacco in Ethiopia was started 90 years ago, the intention of those laws was not to protect the public from tobacco epidemic. Their objectives were to sustain monopoly ownership of tobacco product. They were motivated to maintain the production as a source of government income. For several years, institutionally tobacco production was under the control of its producers until 2009. However, it is by virtue of Article 22 (Proclamation No. 661/2009), tobacco product regulation became under the Food, Medicine and Health Care Administration and Control Authority (herein after referred as, FMHACA) and it requires securing a special permit for the importation, exportation or wholesale of tobacco products before engaging in these ventures.

It is further stated that the content, manufacture, import, export, distribution, sales, use, advertisement and promotion, packaging and labeling and disposal of tobacco products shall be in conformity with regulations issued under the proclamation (Ibid). But the problem of this proclamation was that it totally ignored the issue of public health safety in general and banning smoking in public places in particular. Even it does not regulate the way how the product is being used both by smokers and the area where smoking is allowed. It did not lie any ground about protecting the public.

After four years, however, the implementation regulation was enacted. This regulation provides as a principle, that no person may smoke tobacco in a place for public gathering or use (Regulation No. 299/2013, Art 36, 1). These places for public gathering or use shall include rooms of health institution; class rooms of educational institution; public conveyances; dining places like hotels and restaurants; and such other places prohibited for smoking as may be determined by the appropriate organ (Regulation No. 299/2013, Art 36, 2), a-e), (3). This legislative restriction on where to smoke is the first in its kind in Ethiopia. Thus, this writer holds that legislative ban of smoking in public places was not introduced until 2013 and such restriction was a fundamental shift to protect the public from SHS. Yet due to various reasons it was ineffective among others, smoking areas are left to be identified by the authority. Moreover, the Authority did not identify such areas and to the worst smoking is allowed in a designated area.

Ethiopia made a phenomenal move on tobacco control while it ratified the FCTC (Proclamation No. 822/2014). It should be noted that Ethiopia signed the FCTC on Feb, 25, 2004 (WHO Report on the Global Tobacco Epidemic, 2017). This was a great step to join the global response to tobacco control ratifying the 
FCTC in January 2014 after a decade of its signature. It could be typically considered as an indication of acknowledging that the tobacco epidemic is a major threat to public health. Moreover, the ratification of the FCTC justified a government's duty to "implement effective legislative, executive, administrative and/or other measures", as provided in Art.8 of the FCTC. The FCTC in its preamble requires parties to enact laws and policies that meet minimum international standards that enable to save the public from tobacco health epidemic. Therefore, it is presumably a landmark development in Ethiopia's fight against smoke related health and social problems.

After the ratification of the FCTC, a new directive was enacted to enhance the implementation of the Convention. To that effect, the preamble of the Tobacco Control Directive, 28/2015 states that FMHACA is mandated to undertake and implement the convention and maintain effective implementation of smoke free regimes of the FCTC. The preamble of the directive clearly stated that tobacco consumption has been scientifically confirmed to cause serious ailments including cancer, respiratory disease, cardiac and blood vessel diseases; disability as well as death. In so doing it clearly acknowledged that smoking is serious health, social, economic and environmental consequences in Ethiopia for the first time. Furthermore, exposure to tobacco smoke causes serious health problems, death, and disability to nonsmokers exposed to the smoke, and its control is found a must measure to say the least. Therefore, a cumulative reading of Art, 14 (1) and 2 of the directive envisages that overall objective is to protect public health from the devastating health, social, environmental and economic consequences of tobacco consumption and exposure to tobacco smoke and, as appropriate, to give effect to Ethiopia's obligations undertaken under the WHO FCTC and its implementing guidelines and protocols.

The directive prohibits smoking in any part of indoor public places, indoor work places, and on public conveyances. The prohibited indoor work places and public places covers from health and education institutions... to railway stations, airports and bus stations ${ }^{17}$. Moreover, it is also prohibited to smoke anywhere within the outside premises any place that provides services primarily to children or youth under the age 18 including playgrounds, kindergartens, education facilities, other places where children congregate, and youth centers.

However, as art 15 of the directive envisages, smoking is allowed in government offices, rooms of education and healthcare service, tobacco may be smoked if the owners of the prohibited public or work places provide a designated room for smoking. Similarly, smoking in the outdoor premises of universities, colleges and other higher education facilities, and public transport stations is allowed in a smoking designated area as envisaged in Art 15, (3). In both situation, smoking

\footnotetext{
${ }^{17}$ Art. 14 (2) a-h), Health and education institutions; restaurants, hotels and other eating places; bars, night clubs, cafes, and recreational clubs; prisons, police stations, and any government offices; corridors, reception areas, lifts, stairwells, toilets and laundries of offices and work places; factories and shopping malls; cinema, theatre and video houses and concert halls, and such other halls or places of performance, or any other entertainment; sites of attraction and sport places; and railway stations, airports and bus stations.
} 
requires a provision of designated area by the business owners. Accordingly, it is the duty of the owner or other responsible person of the public place or conveyance or, in the case of a workplace the employer or other appropriate person to take all reasonable steps to enforce or ensure compliance with the smoking prohibition provisions ${ }^{18}$.

Be that as it may, however, the content of such provisions should be seen in terms of whether it could bring the intended objective of protecting the public is contested for many reasons. Firstly, banning of smoking in public places is limited in allowing ventilation systems, designated smoking rooms and designated smoking areas. The legislative measures, which allow smoking in a designated area, are one of the hidden efforts of tobacco industry to undermine the effectiveness of banning smoking at large ${ }^{19}$. This has been proved in different countries for laws that do not require $100 \%$ smoke-free public places are ineffective in protecting public health (Agbenyikey, Wellington, Gyapong, Travers, Breysse, McCarty et al., 2010). Such partial smoke-free laws, ventilation systems, designated smoking rooms and designated smoking areas do not protect the public and workers from the deadly effects of $\mathrm{SHS}^{20}$. There are conclusive evidences that engineering approaches do not protect against exposure to tobacco smoke ${ }^{21}$. Designated smoking rooms even with ventilation do not protect people from SHS because smoke inevitably leaks into nonsmoking areas, ventilation does not remove SHS, and workers still need to enter the room to provide services (Leavell, Muggli, Hurt, \& Repace, 2006). Smoke from designated smoking areas easily moves from the smoking areas to where smoking is not allowed. In this regard, it has been evidenced in Switzerland, nonsmoking areas in venues with designated smoking areas had indoor air pollution 2.7 times greater than completely smoke-free venues (Huss, Kooijman, Breuer, Bohler, Zund, \& Wenk, 2010). Therefore, there is no safe level of exposure to tobacco smoke and the only effective way to protect people is to enact a comprehensive smoking banning laws.

It is clear that the FCTC requires countries to pass policies restricting where smoking can occur in public environments. But it has been observed that for years that the tobacco industry has attempted to undermine policies to protect people from $\mathrm{SHS}^{22}$. It is against this fact that the content of both the regulation and the directive in Ethiopia allowed smoking in a designated area. Therefore, from the very outset the problem of the existing legislative restrictions lays on permitting smoking in a designated room. Such ineffectiveness was also evidenced in Hawassa city due to the absence of such designated area for smoking

\footnotetext{
${ }^{18}$ Art. 15 (1). The duty of owner or other responsible person of the public place or conveyance, or, in the case of a workplace the employer or other appropriate person includes, avoiding a placement of ashtrays in any place under his control and posting a clear and prominent notices in Amharic or English, or in the Region's local language and in Amharic that smoking is not allowed. (cumulative reading of Art 15, (3) \& (4)).

${ }^{19}$ (Smoke-free environments, 2011) http://www.tobaccofreecenter.org/.

${ }^{20}$ Ibid.

${ }^{21}$ (WHO, Guidelines on Protection from Exposure to Tobacco Smoke) Art. 8, Principle 2.

${ }^{22}$ (World Health organization, 2007), Protection from exposure to second-hand smoke: policy recommendations.
} 
as provided in the regulation and directive at all in any of the service giving hotels and institutions in the city ${ }^{23}$.

\subsection{Banning Smoking in Public Places and Institutional Challenges}

The regulatory framework of tobacco product had been controlled by various bodies. At the early stage, it was under the Ministry of Finance and Board and moved to the Ministry of agriculture. But later on, the National Tobacco and Matches Corporation was established and took over this role. But a radical shift of regulating tobacco product was made after the establishment of NTE Ethiopia S. C in 1992. The monopoly of regulating tobacco product was transferred to the NTE by Proclamation No 37/92. Thus, institutional structure of the tobacco regulatory framework was under the control the monopoly of the NTE for long period of time.

But after 2009, the role of regulating tobacco product has been transferred to the FMHACA. The FMHACA is mandated to enforce tobacco control laws in general and the FCTC in particular (Regulation No. 189/2009, Proclamation No. 822/2014). At the regional level, the bureau of health is entrusted to take such responsibility. At the Federal level, the FMHACA is entrusted with the power to implement such laws with it wider mandate with very short human resource and capacity. Personnel engaged in the enforcement process critically opined that there is shortage of human resource, lack of coordination between the FMHACA with regional respective bureau (Ibid). It was also submitted that only little attention was paid to control tobacco product while compared to other regulated products. The most important problem in the institutional framework is the FMHACA has been conferred to ensure the safety of food, medicine, health care institutions and professionals along with enforcing tobacco control legislation in unthinkable if not impossible. These functions are very challenging given current human resource capacity of the sector ${ }^{24}$.

The authority has a vision of providing quality health services and products to all citizens. Among its duties almost the authority is mandated with numerous duties from initiating policies framework for health and health related services, professionals, and food and food related products. As per to Proclamation No. $661 / 2009$, the only power given specifically regarding to tobacco product focuses on regulating the content, manufacture, import, export, distribution, sales, use, packaging and labeling, advertisement and promotion, and disposal of tobacco products. The Authority is also empowered with a mandate to regulate the $4 \mathrm{Ps}^{25}$.

\footnotetext{
${ }^{23}$ (Interview with Amare Asrat), officer at Hawassa city, Health Department, Health and Health Related Services and Inputs Quality Control, core process.

${ }^{24}$ (Interview with Ato Zemen Legesse), Core process owner, Hawassa city, Health Department, Health and Health Related Services and Inputs Quality Control (HHSIQC).

${ }^{25}$ Practice stands for: Health care practices; Premises: Which includes, Healthcare facilities, Food establishments, Medicine Facilities, Health related Facilities, Port inspection sites and Health related facilities; Professional: all Health professionals; Product: From production up-to consumption of Medicines, Medical equipment and devices, Food and Food supplements, Herbal products, Cosmetics, Complimentary and traditional Medicines.
} 
The staff composition in the Authority is composed variety of professionals ${ }^{26}$. Yet it is unfortunate this authority is paradoxically mandated with several duties on food products than tobacco product controlling. There is a shortage of human resource, lack of coordination between the FMHACA with regional respective bureau.

\subsection{Legal and Institutional Framework: Some Evidences from Hawassa City}

It is clear that there was no law which regulates the issue of tobaccos and smoking in public places at the regional level until 2013. Regulation No. 299/2013 gives as a clue to this effect allowing regions to enact laws to implement the regulation. Yet there is no regulation or directive to this effect in the SNNPR region. On top of that, the new directive already made its scope wide by claiming its applicability at the national level (Directive No 828/2015 Art 4, (1),). The directive clearly provides that the scope of application covers whole nation, but it does not provide who would be in charge to enforce both the directive at the regional level as indicated in its Art 4. It only provides that an appropriate organ will be responsible to enforce the directive and these organs are many as defined in Art 2, $24)^{27}$. Yet, this scope of application of the directive is unimplemented in the region at large where Hawassa city is not an exception. Thus, with the absence of regional directive to implement the legal regime of banning smoking in public places, the FCTC and its implementing directives are inapplicable across the nation and the case of Hawassa city is not an exception to this. In this regard, the city of Mekele introduced smoke free laws at public places with measure and became the first to ban smoking in public places. It is provided that anyone who trespasses the ban will be subject to a fine of $1000 \mathrm{ETB}^{28}$. There is no such clear legislative measure taken in the SNNP region in this regard. The only legal framework to be mentioned in as to health and related issues are envisaged in three different proclamations (Proclamation No. 127/2009; 133/2010 and 161/2015).

In the regional setup, Health and Health Related Services and Inputs Quality Control Authority (here in abbreviated as, HRSIQCA) is established under the bureau of health in the region to control service and related inputs in the region (Proclamation, No. 127/2009, Art. 4/25). As per to Art. 27, (3) the authority was mandated with controlling the wellness and quality of food, drinks and medicines and necessary measures in accordance with the law. But this was repealed

\footnotetext{
${ }^{26}$ These include, public health professionals, nurse, medical laboratory technologist, environmental health professional, general medical practitioner, health science professional, pharmacist, data administrator, librarian, Agro-chemist, health science technician, medical equipment maintenance engineer and information technologist.

${ }^{27}$ Appropriate organ means the federal and regional government organ in charge of activities, including health, trade, education, transport, culture and tourism, customs and revenue, or advertisement, and other government organ responsible to execute regulated activities under this directive. ${ }^{28}$ (Sobecki, 2015). Ethiopia Implements Smoke. http://www.businessinsider.com/afp-stubbing-it-out-ethiopia-implements-smoking-ban-2015-8?IR=T
} 
by Proclamation No. 133/2010 and the new law provided related responsibilities but with slight differences, like supervise the qualities and well-being of food, beverage and medicine; take measure in accordance with the law. Thus, there is no such a clear legal indication conferred to the bureau of health of the region and department of Health in Hawassa city in particular.

Accordingly, it could be argued that there are no clear provisions which could tell us that this authority is responsible for the enforcement despite its claim. But one may argue that from the nature of the product and basing its practical due, the health bureau is an appropriate body to endure the observance of the federal laws. The authority to ensure the implementation of tobacco control legislation and take measure in accordance with the law was not stated clearly nor does Art 40 of Proclamation 133/2010. However, still this power is repealed by another proclamation (Proclamation No. 161/2015). Furthermore, there are no such laws or directives or manuals enacted by the regional authority ${ }^{29}$.

Moreover, institutionally, there is incomparable shortage of competent human power and budget constraints to control regulated products like tobacco products and inspection of smoking in public places. The structure of health and health related inputs and product quality control core process was established eight years ago when there was no legal duty to enforce tobacco control regulations in general and smoke banning laws in particular. As a result, there are only five officers in charge to enforce both health and health related services and products in the city where there are more than 4000 business and other establishments which provide various services $^{30}$, let alone enforcing the directive enacted at the federal level.

In Hawassa city, it could be argued that institutionally the department of health may be held responsible for the proper monitoring and enforcement of legislation that is applied across the nation pertaining to tobacco control. But the department of health in Hawassa city claimed that their duties are being hampered by the unclear nature of the directive and regulation and lack of coordination between tobacco controlling sectors ${ }^{31}$. Moreover, it has been also admitted the existence of structural difficulties during the enforcement where authorities are highly fragmented across several departments, making it difficult to communication and enforcement measures. The interview conducted for this research revealed that there are insignificant efforts made in Hawassa so as to enforce laws banning smoking and protect the public from smoking hazard as the department of health that is mandated cannot handle the effective implementation of the existing banning provisions given its current human and resources ${ }^{32}$. It was noted that only few consultative meeting and awareness creation forums carried out with various stakeholders, owners of bar and restaurants, hotels on the new directive ${ }^{33}$. The only thing the department of health did in this regard

\footnotetext{
${ }^{29}$ Interview with, Zemen Legese, Supra N 24.

${ }^{30}$ Interview with, Amare, Supra N, 23.

${ }^{31}$ Ibid.

${ }^{32}$ Interview with, Amare, Supra N 23

${ }^{33}$ The third quarter performance report of the health department, HRIQC, core process 2016, unpublished, P. 17.
} 
was holding public awareness creation forum on how to identify places where smoking is not allowed 2015/2016 $6^{34}$.

In any case the implementation of the existing legal restrictions cannot work and protect the public at large. This is for various reasons. It is already argued that the existing laws in Ethiopia allow smoking in a designated room for smoking except for schools, health centers, and government institutions. However, it should be noted that there are many reasons why allowing designated smoking is not preferable. Designated smoking rooms even with ventilation do not protect people from SHS because smoke inevitably leaks into nonsmoking areas, ventilation does not remove SHS, and workers still need to enter the room to provide services (Leavell, Muggli, Hurt, \& Repace, 2006). Furthermore, this has been proved as restaurants with designated smoking areas had more than twice the amount of particle pollution than restaurants with $100 \%$ smoke-free policies $^{35}$. Where restaurants and bars were allowed to set up ventilated designated smoking rooms, it is found that there were no significant decreases in exposure to SHS, among workers in environments with partial restrictions on smoking (Fernandez, Fu, Pascual, lopezm, Perez-Rios, Schiaffio, et al., 2009).

Furthermore, it is seen in many countries that enforcing ventilated designated area is costly and even there is no such designated area in the first place to test enforcement of such provision in Hawassa city. To that end, there are studies that found smoking rooms are not practical due to the technical demands and costs associated with the building, operation and maintenance of the rooms in different countries (Wanm, Wu, Chan, Chao, \& Yeung, 2010). Designated smoking rooms are also costly to construct, maintain, and enforce (Leavell, Muggli, Hurt, \& Repace, 2006). First, it is difficult to implement where no public facilities arranged such designated places to accommodate both smokers' and nonsmokers' wishes (Rabin \& Sugarman, 2001), Moreover, it would be difficult to isolate exposure to SHS from nonsmokers in public places such as in a restaurant, on public transportation, or in a mall (Ibid). In many cases, there is no economically feasible way to accomplish separate air supplies through separate ventilation systems (Ibid).

It is in line with this fact that the implementation of smoking banning legislative observed in Hawassa city. In this regard, it was observed that there were no significant implementation measures taken against those individuals who failed to observe what is provided to comply. There are no business establishments that prepared the minimum required designated area for smokers. As a result, personal observation in public places such as, bust stations, night clubs, public offices and education institutes and revealed this fact ${ }^{36}$. It was observed that all night clubs did not comply with the law in providing designated smoking areas. Despite the fact that some caterings and clubs posted the notice but smokers do

${ }^{36}$ Personal observation of the author some selected business establishments during the study period.
} 
not observe such notice and comply to the owners or managers of such caterings, consumers smoke as they wish at the presence of many nonsmokers.

\subsection{Enforcement of Smoke Restrictive Laws}

There is no doubt legislative banning requires strong authority or authorities responsible for enforcement, and it should include a system both for monitoring compliance and for prosecuting violators. The issue of protecting the public from hazardous effect of tobacco needs such unequivocal legislative measures and its effective enforcement. Legislative restriction where to smoke is designed to achieve certain policy objectives as such. To that effect, enactment of the smoke restricting laws is a necessary pre-condition to ensure that smokers and nonsmokers enjoy a smoke-free environment when frequenting public places. To be sure, effective legislation should impose legal responsibilities for compliance on both affected business establishments and individual smokers, and should provide penalties for violations, which should apply to businesses and possibly smokers ${ }^{37}$. In so doing, the compliance with smoking bans would be ensured by imposing monetary fines on both individuals and businesses, although enforcement efforts should focus on the latter. The legislation should place the responsibility for compliance on the owner, manager or other person in charge of the premises, and should clearly identify the actions he or she is required to take. The law mandates owners of public places as well as employers to enforce this section of the law. The concerned officials in public places are required to put out signs that forbid smoking, prevent people from smoking outside the designated areas, and avoid practices such as placing ashtrays.

It is clearly indicated in the FCTC Guideline to implement Article 8 that parties are obliged to deal with criminal and civil liability while the restriction is not complied. The enactment of Directive No. 28/2015 and its objective to enforce the FCTC's did not imply that it has not been implemented effectively. The enforcement measures reported in 2016/17 of Hawassa city were insignificant. This argument is supported in the interview conducted with the key informant as a move made to enforce legislation banning smoking was not remarkable. There is no clear plan to examine the effect of the FCTC and its implementing directive during the periods of 2016-2017. It is noted that the legislation of which prohibits smoking should specify fines or other monetary penalties for violations. Most importantly, penalties should be sufficiently large to deter violations or otherwise they may be ignored by violators or treated as mere costs of doing business. Normally it is believed that larger penalties are required to deter business violators than to deter violations by individual smokers, who usually have fewer resources. The legislative restriction should also allow administrative sanctions, such as the suspension of business license (FCTC Guideline, Art 8).

Therefore, under the Ethiopian laws discussed in this research, it was found that there are no punitive measures indicated against a failure to comply the

${ }^{37}$ Advancing the right to health: the vital role of law. (2017), Geneva: World Health Organization. 
restriction. Accordingly, the effectiveness of banning smoking in public places is challenged by poor enforcement measures envisaged in the directive and other existing proclamations and regulation. Moreover, it is proved that there no designated area for smoking as provided in the regulation and directive in any of the service giving hotels and institutions. This claim is proved through the inspection made the department of health of the city itself. According to the desk of health, there is no single business establishment that assigned designated places as provided in the directive ${ }^{38}$. To that effect, the office ordered all business establishment to assign a designated area as prescribed in the directive and warned otherwise that noncompliance thereof entail criminal consequence as to Art 53 of Proclamation No. 661/2009 but in vain. Consequently, it is found that the mere existence of smoke banning laws in Ethiopiain general and Hawassa city in particular does not guarantee the observance of the objective of protecting the public from the SHS threat without clearly defined enforcement measures.

Smoking restrictions require a mechanism for monitoring the behaviors of people in smoke-free areas. They also require a means of sanctioning individuals who violate the smoking restrictions, as well as owners and staff members of smoke-free facilities who fail to enforce or abide by regulations. This assertion does not work here as the Ethiopian legal framework provides only the duty of the owner or other responsible person of the public place or conveyance, or, in the case of a workplace the employer or other appropriate person to take all reasonable steps to enforce or ensure compliance with the smoking prohibition provisions of this directive. These reasonable steps to be taken only include, post clear signs at entrances and other appropriate locations indicating that smoking is not permitted by law; supervise the observance of regulations; and ask the person to stop smoking, ask the person to leave the premise or public conveyance, discontinue services if appropriate, and notify law enforcement agents (Directive No 828/2015, Art 16). But there is no measure provided in failure of even such duties in terms of fine penalty and administrative measure.

Legislative restrictions lack any measures if not complied with and thus the effectiveness of banning smoking in public places is challenged by poor enforcement measures provide in the directive and weak reaction made implement the existing laws. For instance, those duties of compliance on owners to put out signs that forbid smoking, prevent people from smoking outside the designated areas, and avoid practices such as placing ashtrays remains without clear punitive measure. Thus, the issue of such responsibility in Ethiopian case is doomed despite that Directive No. 28/2015 referred the violation of the directive to be held criminally responsible in accordance with the Ethiopian criminal code, the FMHACA Proclamation No. 661/2009. It was also argued in favor of this omis-

\footnotetext{
${ }^{38} \mathrm{~A}$ Circular letter written on $27 / 4 / 2017$ to all business establishments and hotels in Hawassa city. ${ }^{39} \mathrm{~A}$ brochure of the health desk wrongly provides that there is a criminal liability against a violation of Art. 22 of Proc. No. 661/2009 and Directive No, 828/2015 is not complied. A hard copy of the brochure is available with the author.
} 
sion as per to proclamation $661 / 2009$ too and this was the position of the department of health in Hawassa city to ${ }^{39}$. The base of this argument is Art 22 of the Directive and Art 53 of Proc. No. 661/2009. But such argument is not tenable for there is no any punitive measure or penalty provided in proclamation regarding violation against provisions that provide for banning tobacco smoking in public places. Moreover, it should be noted that what is punishable under Art 53 , (1) (e), is a violation of advertisement of tobacco product and not violation of smoking in public places. This is totally misleading as the regulated public and business establishments could not be held responsible. There is no as such penalty without clear legal provisions. The main reason being such application goes against the known Latin maxim "nullum crimen sine lege" as prescribed in the Criminal Code Art, 2 (1) "No crime unless specified by law and "nulla poena sine lege" literarily meaning "no penalties other than prescribed by law" as indicated in sub article (2).

\section{Conclusion}

Although the prevalence of tobacco smoking in Ethiopia is not well researched and documented, the issue tobacco control legislation goes back to 90 years. There were various laws enacted since then but their objectives were to sustain monopoly ownership of tobacco product. These legal frameworks had been motivated to maintain the production as a source of government income. No legislative provisions were meant to protect the public from tobacco health threat; nor it restricted where to smoke.

The analysis of various primary and secondary data revealed that legislative restriction or banning smoking in Ethiopia was introduced for the first time by the virtue of Regulation No. 299/2013 in 2013. Moreover, it is noted Ethiopia acknowledged the ramification tobacco product in general and smoking in public places in particular and ratified the FCTC and implementation Directive No $828 / 2015$. It is found that these legislative frameworks clearly recognized the fact that tobacco products and smoking cause serious health and affected the social, economic and environmental consequences and expected it control exposure to tobacco smoke which causes serious health problems, death, and disability to nonsmokers exposed to the smoke.

However, the existing scenario revealed that these recent legislative restrictions of smoking are not comprehensive as it allowed smoking in designated area in terms of its content. Moreover, there are various reasons why legal and institutional frameworks are ineffective. Firstly, allowing smoking in a designated area is by itself undesirable for the enforcement of such restriction has been proved ineffective in many jurisdictions and the same is revealed in this study. In this regard, lack of punitive measures for noncompliance of existing restriction made it flaw in many aspects. Secondly, there are no designated places arranged in Hawassa city and these laws failed to provide punitive measures even if the regulated business establishments failed to comply. It is concluded that 
neither the Regulation No. 299/2013, nor the FCTC along with its implementation directive implemented to protect the public from tobacco epidemics and threat.

Institutionally tobacco regulations were controlled under the monopoly of the NTE for a long period of time until 2009. But at the federal level, Proclamation No. 661/2009 conferred the FMHACA the power of controlling tobacco manufacture, import, export, distribution, sales, use, packaging and labeling, advertisement and promotion, and disposal of tobacco products though this does not include banning in smoking in public places. However, Regulation No 299/2013 and Proclamation No, 822/2014 clearly mandated it ensure to the observance of legislative restriction. Thus, the FMHACA is expected to implement this few provisions with it wider mandate with insufficient human resource and capacity. But there is shortage of human resource, lack of coordination between the FMHACA with regional respective health bureau and little attention paid regarding tobacco control with respect to other issues. The most important problem in the institutional framework is that the FMHACA has been conferred to ensure the observance of laws related to safety of food, medicine, health care institutions and professionals. Thus, observing the enforcement of tobacco control legislation has become more unthinkable if not impossible and the same inefficiency observed mutandis mutatis in the case of Hawassa City.

Accordingly, it is suggested that legislative restrictions should be comprehensive and restrict smoking in all places without designated areas so as to achieve its intended goal and Ethiopia should take a lesson from successful developing countries in this regard. Moreover, the city of Hawassa should issue local ordinance with clearly defined duties and responsibilities to ensure the observance of restriction of smoking in public places and institutional framework should be enhanced from the federal to the local level. Moreover, further research is needed to check the impact of laws banning smoking in Ethiopia and the extent of prevalence of smoking and its consequences.

\section{Acknowledgements}

I would like to acknowledge Hawassa University for funding this study. I am also grateful to the anonymous reviewers and staff of the BLR while remaining errors are of mine.

\section{Conflict of Interest}

Declared none.

\section{References}

Abiye, Y., \& Dawit, E. (2017). Ethiopia's First Tobacco Survey Reveals Alarming Trend (Vol. 22, No. 1104). The Reporter.

http://thereporterethiopia.com/article/ethiopias-first-tobacco-survey-reveals-alarmingtrend-bahir-dar-bans-khat

Addis Admas Newspaper (2015). Amharic Version. http://www.addisadmassnews.com/ 
Agbenyikey, W., Wellington, E., Gyapong, J., Travers, M. J., Breysse, P. N., McCarty, K. M. et al. (2010). Secondhand Tobacco Smoke Exposure in Selected Public Places (PM2.5 and Air Nicotine) and Nonsmoking Employees (Hair Nicotine) in Ghana.

Boyle, P., Nigel, G., Jack, H., John, S., \& Witold, Z. (2004). Tobacco and Public Health: Science and Policy (pp. 669-668). Oxford: Oxford University Press.

Cabrera, A., \& Gostin, O. (2011). Human Rights and the Framework Convention on Tobacco Control: Mutually Reinforcing Systems. International Journal of Law in Context, 7, 285-303. https://doi.org/10.1017/S1744552311000139

Carpenter, C., Sabina, P., \& Casey, W. (2011). Public-Place Smoking Laws and Exposure to Environmental Tobacco Smoke (ETS). American Economic Journal: Economic Policy, 3, 35-61. http://www.jstor.org/stable/41238102

Carrell, S., Johnson, C. L., Stanley, L. C., Thompson, J., \& Tosti, S. (1998). Changing Public Policy around Tobacco Control in the COMMIT Communities. Smoking and Tobacco Control Monograph No. 6.

Chapman, S. (2007). Public Health Advocacy and Tobacco Control: Making Smoking History. University of Sydney, NSW, Blackwell Publisher. https://doi.org/10.1002/9780470692479

Chapman, S., Borland, R., Scollo, M., Brownson, R., Dominello, A., \& Woodward, S. (1999). The Impact of Smoke-Free Workplaces on Declining Cigarette Consumption in Australia and the United States. American Journal of Public Health, 89, 1018-1023. https://doi.org/10.2105/AJPH.89.7.1018

Decree 37/59 A Decree to Amend the Tobacco Regie Proclamation 30/1942.

Dereje, N., Abazinab, S., \& Girma, A. (2014). Prevalence and Predictors of Cigarette Smoking among Adolescents of Ethiopia: School Based Cross Sectional Survey. Journal of Child and Adolescent Behavior, 3, 182. https://doi.org/10.4172/2375-4494.1000182

Drope, J. (2011). Tobacco Control in Africa People, Politics and Policies. London: International Development Research Center, Anthem Press. http://www.idrc.ca

Fernandez, E., Fu, M., Pascual, J. A., lopezm, J., Perez-rios, M., Schiaffio, A. et al. (2009). Impact of the Spanish Smoking Law on Exposure to Second-Hand Smoke and Respiratory Health in Hospitality Workers: A Cohort Study. PLoS ONE, 4, e4244. https://doi.org/10.1371/journal.pone.0004244

Global Youth Tobacco Survey GYTS (2005). Conducted in Secondary Schools in Addis Ababa-Ethiopia. http://www.afro.who.int/index.php?option=com_docman\&task

Goodman, J. (2005). Tobacco in History: The Cultures of Dependence. London: Routledge.

Huss, A., kooijman, C., Breuer, M., Bohler, P., Zund, T., Wenk, S. et al. (2010). Fine Particulate Matter Measurements in Swiss Restaurants, Cafes and Bars: What Is the Effect of Spatial Separation between Smoking and Nonsmoking Areas? Indoor Air, 20, 52-60. https://doi.org/10.1111/j.1600-0668.2009.00625.x

Jaloha, R. C. (2008). Tobacco Use and Behavior (p. 178). New Age International (P) Ltd. https://doi.org/10.1186/s12889-015-1820-4

Lakew and Haile (2015). Tobacco Use and Associated Factors among Adults in Ethiopia: Further Analysis of the 2011 Ethiopian Demographic and Health Survey. BMC Public Health, 15, 487.

Leavell, N. R., Muggli, M. E., Hurt, R. D., \& Repace, J. (2006). Blowing Smoke: British American Tobacco's air Filtration Scheme. British Medical Journal, 332, 227-229.

Legal Notice No, 70/1945, Tobacco Growing and Leaf Purchasing Regulations. 
Legal Notice No. 227/1959, the Tobacco Regie Regulations.

Mattias, Ö., Jaakkola, M. S., Woodward, A., Peruga, A., \& Prüss-Ustün, A. (2011). Worldwide Burden of Disease from Exposure to Second-Hand Smoke: A Retrospective Analysis of Data from 192 Countries. The Lancet, 377, 139-146. https://doi.org/10.1016/S0140-6736(10)61388-8

Meier, B., \& Donna, S. (2006). The Fourth Pillar of the Framework Convention on Tobacco Control: Harm Reduction and the International Human Right to Health. Public Health Reports, 121, 495-500.

Meier, M. (2004). Breathing Life into the FCTC: Smoke Cessation and the Right to Health. Yale Journal of Health Policy, Law, and Ethics, 5, 137-192.

Prabhat, J., Chaloupka, F. J., Moore, J., Gajalakshmi, V., Gupta, P. C., Peck, R., Asma, S. et al. (2006). Disease Control Priorities in Developing Countries (pp. 869-886). The International Bank for Reconstruction and Development, Oxford University Press.

Proclamation 181/1999, The Transfer of the Monopoly Right of the National Tobacco Enterprise to the National Tobacco Enterprise (Ethiopia) Share Company.

Proclamation No. 1/1995, FDRE Constitution.

Proclamation No. 127/2009. Proclamation to Determine Rights and Duties of the SNNPRS Sector Offices Executive Organs.

Proclamation No. 133/2010. Proclamation to Re-Determine the Power and Duties of the Executive Organs of Southern Nations, Nationalities and Peoples Regional State.

Proclamation No. 161/2015.Redefining the Powers and duties of Executive Organs of Southern Nations, Nationalities and Peoples' Regional State.

Proclamation No. 197/1980, National Tobacco and Matches Corporation Establishment.

Proclamation No. 30/1942, A Proclamation to Establish a State Monopoly in Respect of Tobacco, Matches and Pocket Lighters.

Proclamation No. 37/1992. the National Tobacco Enterprise.

Proclamation No. 661/2009, A Proclamation for Food, Medicine and Health Care Administration and Control.

Proclamation No. 822/2014, the FCTC Ratification Proclamation.

Rabin, L., \& Sugarman, D. (2001). Regulating Tobacco. Oxford: Oxford University Press.

Regulation No. 299/2013 Regulation to Provide for FMHACA.

Regulations No. 189/2009. Council of Ministers, Regulation to Establish FMHACA.

Rockville (2010). How Tobacco Smoke Causes Disease: The Biology and Behavioral Basis for Smoking-Attributable Disease: A Report of the Surgeon General. U.S. Department of Health and Human Services.

Roemer, R. (1993). Legislative Action to Combat the World Tobacco Epidemic (2nd ed.). Geneva: World Health Organization.

Serrano, S. (2008). Up in Smoke: The Framework Convention on Tobacco Control, a Worldwide Anti-Smoking Campaign. Florida Coastal School of Law.

http://works.bepress.com/simon_serrano/2

Sims, M., Maxwell, R., Bault, L., \& Gilmore, A. (2010). Short Term Impact of Smoke-Free Legislation in England: Retrospective Analysis of Hospital Admissions for Myocardial Infarction. BMJ, 340, c2161. https://doi.org/10.1136/bmj.c2161

Smoke-Free Environments: Health Harms of Secondhand Smoke. (2011).

http://www.tobaccofreecenter.org 
Smoke-Free Environments: Partial Smoke-Free Laws Do Not Work. http://www.Tobaccofreecenter.org

Smoke-Free Success Stories: Spotlight on Smoke Free Countries, Global Smoke Free Partnership. http://www.tobaccofreecenter.org

Sobecki, N. (2015). Ethiopia Implements Smoke.

http://www.businessinsider.com/afp-stubbing-it-out-ethiopia-implements-smoking-ba n-2015-8

Status of the WHO Framework Convention on Tobacco Control (FCTC).

Sudan Tribune (2015). http://www.sudantribune.com/spip.php?article53625

Tobacco Control Directive No. 28/2015.

Wanm, P., Wu, C. L., Chan, T. T., Chao, C. Y., \& Yeung, L. L. (2010). Removal and Leakage of Environmental Tobacco Smoke from a Model Smoking Room. Journal of Occupational and Environmental Hygiene, 7, 573-584. https://doi.org/10.1080/15459624.2010.504432

WHO (2009). Report on the Global Tobacco Epidemic. Implementing Smoke-Free Environments, Geneva: World Health Organization. http://www.procor.org/globaldialogue/globaldialogue_show.htm?doc_id

WHO (2011). Report on the Global Tobacco Epidemic. Implementing Smoke-Free Environments, Geneva: World Health Organization.

WHO (2011). Smoke-Free Environments Essential Facts. https://www.tobaccofreekids.org/assets/global/pdfs/en/SF_facts_en.pdf

WHO (2012). Global Report on Mortality Attributable to Tobacco. http://apps.who.int/iris/bitstream/10665/44815/1/9789241564434_eng.pdf

WHO Report on the Global Tobacco Epidemic, 2017: Monitoring Tobacco Use and Prevention Policies. Geneva: World Health Organization; 2017. Licence: CC BY-NC-SA 3.0 IGO.

WHO. Guidelines on Protection from Exposure to Tobacco Smoke, Art 8, Principle 2.

World Health Organization (2003). WHO Framework Convention on Tobacco Control (FCTC). http://www.who.int/fctc/text_download/en/index.html

World Health Organization (2007). Protection from Exposure to Second-Hand Smoke: Policy Recommendations.

World Health Organization (2017). Advancing the Right to Health: The Vital Role of Law. Geneva: World Health Organization.

World Health Organization. Tobacco Free Initiative, "The Tobacco Atlas," Section 9, "Deaths". http://www.who.int/tobacco/en/atlas11.pdf

Wu Chuan (2009). State Responsibility for Tobacco Control: The Right to Health Perspective. 